\title{
Logical Description of the Basic Production Processes for the Development of a Construction Production Information Model
}

\author{
${ }^{1}$ Kamil Faritovich Islamov, ${ }^{2}$ Sergey Anatolievich Sovkov \\ ${ }^{1,2}$ Department of Construction Technology and Real Estate Management, Engineering and Construction Department \\ of the Naberezhnye Chelny Institute of the K(P)FU, Kazan Federal University \\ kam@kambox.ru \\ ssa_i@mail.ru
}

Received: 21st August 2020, Accepted: 14th September 2020, Published: 31st October 2020

\begin{abstract}
We considered the questions and problems of detailing the basic production processes for the proposed evolutionary model for the development of automation and control methods for all cycles of construction production in the paradigm of the element-by-minute and per-minute organization of construction work based on the BIM construction model and approved standard construction and technological processes of creating a construction production product. This system includes the proposed work automation and organization methods, which will provide element-by-element planning of the construction of buildings with minute precision of planning detailing, based on the use of pre-developed, tested and approved standard technological processes of construction production, within the framework of the global work schedule. The implementation result of such a system is to obtain an actual facility at the construction site corresponding to the BIM design model of the building, element-by-element and detailed fixation of the technological, financial and time parameters of the actually performed work, as well as resources spent at all stages of construction production. BIM implementation at the stage of construction production will provide an opportunity for automated data exchange with all stakeholders in third-party areas, including interaction and programmatic data exchange with the state construction information system, state supervision authorities, manufacturers of construction materials and equipment, participants in joint financing of construction works and others.
\end{abstract}

\section{Keywords \\ BIM Construction Model; Corporate Estimate Standards; Per-minute Work Schedule; Tomorrow's Order; Target Construction Schedule; BIM Construction Element Passport's Element}

\begin{abstract}
Introduction
One of the options for optimizing the activities of contractors is a more efficient use of the capabilities of the information model of buildings, and the development of "TIM construction flow" on its basis, where the construction process itself is tied to a spatial improvised time tape, where there are all the necessary conditions to produce products in the form of "building element" at the exact time of the construction production schedule by the time of production. Let us consider some of the production processes of building construction using the example of a single-access frame multi-storey residential building.
\end{abstract}

\section{Methods}

The concept of "building element" as the main production indicator is not accidental. Let's take "production of brickwork partitions" on a specific floor (level) as an example. It can be produced by a specific link of masons with the provision of materials and other things necessary for production. Another partition, with simultaneous production at the same level, requires additional masons and production provision or a certain time of execution taking into account the fulfillment of the previous one: if we decide to continue production with the same workers.

Another example includes the elements of the structural frame of a building, columns, beams, wall elements, ventilation shafts, elements of staircases, floor slabs.

At the time of production, a designer and a builder can manipulate only one "building element". This is an axiom that does not require any proof. To simultaneously produce several "elements", we need additional resources: human, material and technical in the form of a computer device and software, for example, Revit, Bentley, Allplan, ArchiCAD, etc.

This concept is equivalent to the conveyor principle, where time is the main indicator of production, characterized by the division of the production process into separate, relatively short operations performed on the specially equipped, sequentially located workplaces of a building under construction. In our case, a specific building element is produced 
according to the real "Location ID in the Project BIM" transferred for unconditional placement on the construction site relative to the building axes, being identical to the project coordinates only in kind.

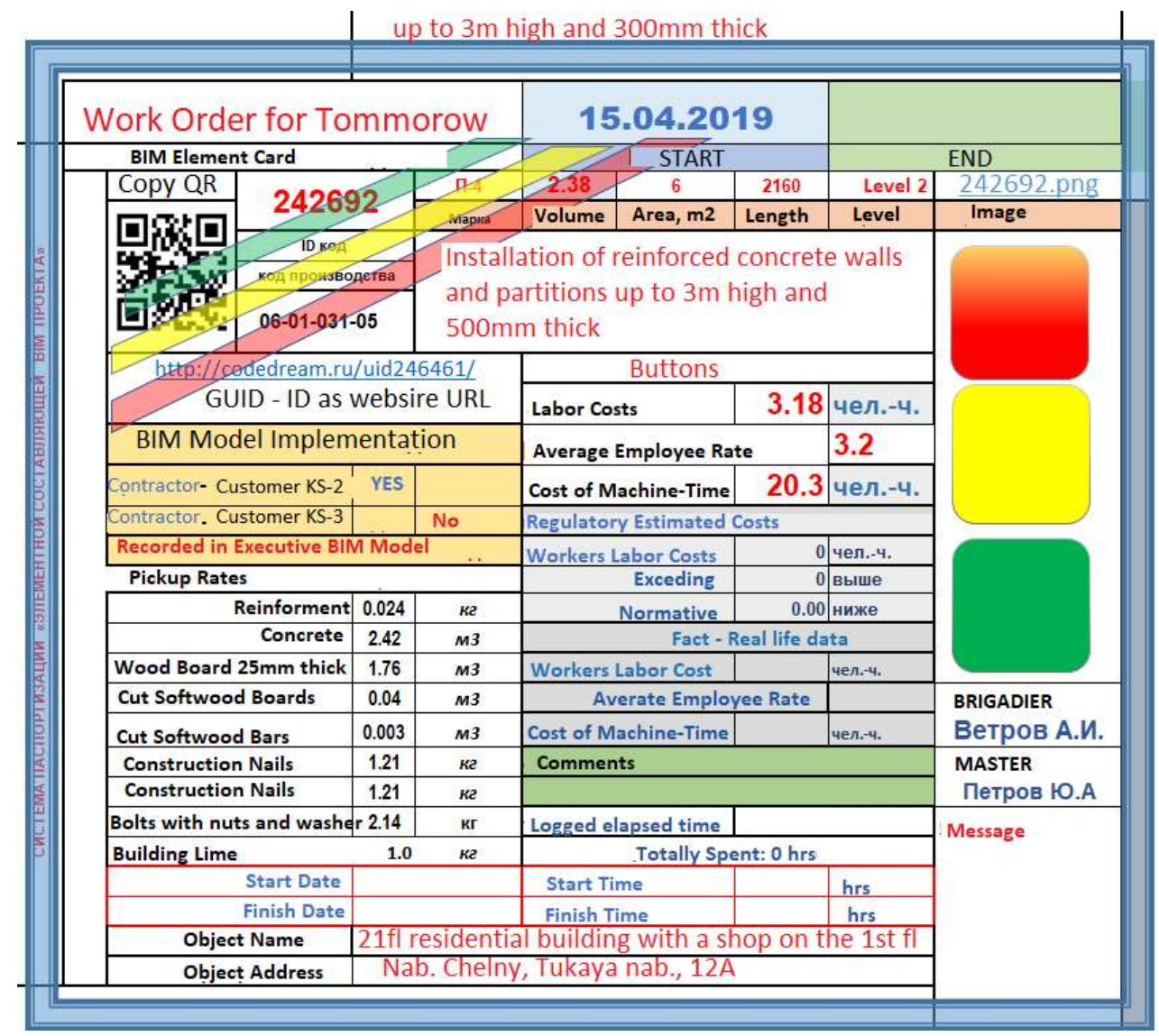

Figure 1: Element's Passport

The basis of the whole process is the "Tomorrow's order" provided to everyone for a specific tomorrow. This "Order" can be the only one or part of the "Piece order for the same works". Each Order has a specific Contractor. The Order has two sections - "production order" and a specific "regulatory block".

Moreover, this is not some kind of abstract order, but a production task for a specific real "building element" from which the building is assembled on a construction site in a strictly designated place (at the project address) at the project location (let's call it, for example, "construction ID address"). Please note that the elements are assembled into various formations in all circumstances, where the basis is a specific "building element" for production - "here and now". Write your text here.

\section{Results and Discussion}

It is possible to bring together the elements identical in production, but different in volume, into specific "assemblies of building elements", which are made under the "piece order" for identical works of a certain part of the building, in relation to the one-entrance residential building under consideration, the most optimal division will be the floor.

Also, when creating a construction information model, the engineer needs to determine the features of identical work. Currently, 2 groups of elements are defined:

1. Building structures manufactured at the construction site, such as masonry, monolithic structures, roll roofs, measured in $\mathrm{m} 3$ and $\mathrm{m} 2$;

2. Prefabricated structures, elements delivered to the facility as finished products, such as columns, beams, wall elements, ventilation shafts, elements of staircases, floor slabs. Their number should be determined in pieces, and when creating the design information model of the building, each element is created with a unique ID number.

The data on the structural element properties, the ability to organize and control the construction process, the accurate work performance, the construction control, the data on the executive model and the subsequent operation of the building fully depend on the Structure details. 
It is obvious that the description of the basic levels of elaboration of CIM LOD 400 elements for the design documentation and projects made in accordance with the Code of Rules SP 333.1325800.2017 "Information Modeling in Construction. The Rules for the Formation of an Information Model of Facilities at Various Stages of the Life Cycle" will have only a minimum approved elaboration level.

The requirements for detailing the construction information model will be determined by the system of organizational and technological preparation and construction management of the contractor, or by the technical requirements of the customer, who has accumulated construction experience and its own system of organization and management of construction production and the operation of buildings.

Here, the balance between the degree of detailing of the construction information model and the labor costs for the creation and application of the construction information model is important. This balance can be determined based on the positive effect of introducing the management process into the organization.

Thus, the "order" notion is not abstract, it is tied to a specific real "building element" or several elements - in a "piece order" tied to the principle of identity, according to the Code of Rules SP 301.1325800.2017 "Information Modeling in Construction. The Rules for the Formation of an Information Model of Facilities at Various Stages of the Life Cycle", identical in production, but different in volume and located at a certain level of the building (floor).

Each building element has an identifier and a corresponding QR code, as well as filling with the necessary data on their construction production, placed in the data warehouse.

The identifier is unique in relation to a specific "building element" and is associated with all information on that building element. The entire history of the building element is associated with the same identifier: from the Project by the "project ID code", by the "ID code of its construction location" and by "QR code of filling with construction production data".

The system basis: the interactive "building element's passport", which contains all the information available from the BIM-model about the corresponding building element, has a unique identifier and location data of the facility under construction.

The regulations on the execution of the "work order" shall have the status of mandatory, if the work is on the "critical path". All other orders are performed in accordance with the "order" issued for production in accordance with the procedure established at the construction site in the "green stripe order", which has some time allowance. Any order can acquire "red" status, if it gets on the critical path. In this case, the process should take place automatically.

It is necessary to put into practice a three-tier system for issuing the production orders.

- $\quad$ The order - which is on the "critical path" - shall have a "red stripe".

- The yellow stripe order (if not taken under control) can be turned over.

- The "green stripe" order - as usual with a time allowance.

A similar approach is used in mechanical engineering, where an alarm is triggered at the workplace by the contractor. Additional costs of resources for debugging such a system within the framework of the contractor organization are justified by the gain from the timely delivery of the Contract Facility with the required quality level.

This system assumes that the "red stripe order" should be performed with the highest priority and any available resources.
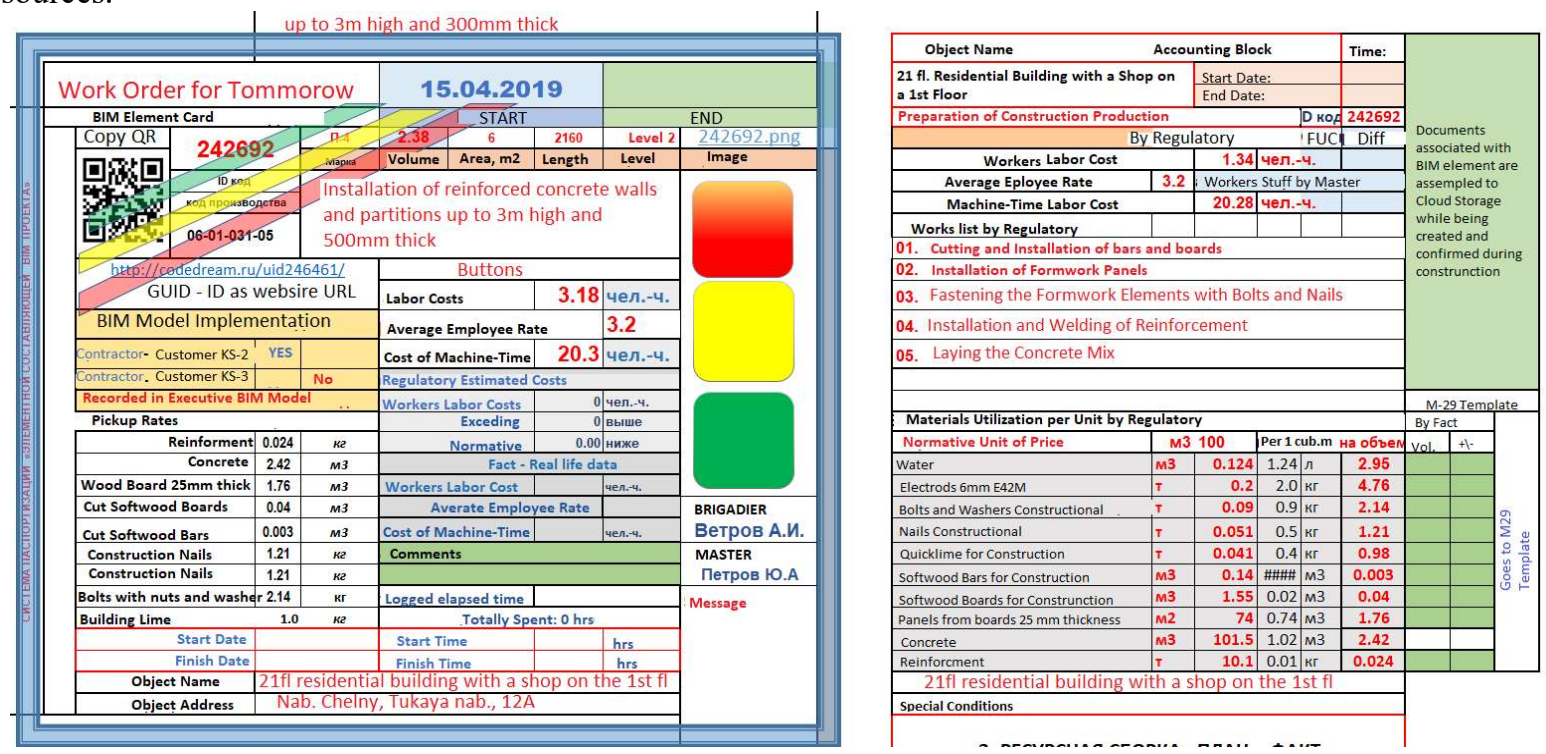


\section{Figure 2: Status Colorful Indication}

The "red order" status should be discussed with the contractor as mandatory and unconditional. It is possible to provide this status with an additional Order, with which the contractors shall agree. Such a provision can also be specified when hiring.

Certification of all building elements is necessary as the basis for the construction model development. It will streamline both the preparation process and the production itself, create the preconditions for transforming the construction process into the conveyor principle of detailed planning.

The certification process is carried out at the time of demand - here and now. In fact, the output form from the BIM Project represented as a "specification of building elements" is generated automatically from the database of all elements of the BIM model of the building under construction. Creation of the "element's passport in a matter of minutes - where the matrix of "Passport when transferring a line from the "List of building elements" is placed on the assembly stack "Certification of building elements" - here and now.

The procedure for forming "Production orders" from the initial data from the BIM Project is provided by the diagram in Fig. 3. An inherent feature of the proposed system is the principle of the impossibility of missing a building element from the field of vision, first of all, of the TDD engineer responsible for Certification. The list of elements does not depend on the human factor - an automated script for the BIM model processing will provide a list of all elements of the BIM model.

The following diagram also provides a matrix for generating the Construction Production Schedule, where each element or assembly of building elements shall have a production time. The degree of importance is determined by the sequence and technology of the production process.

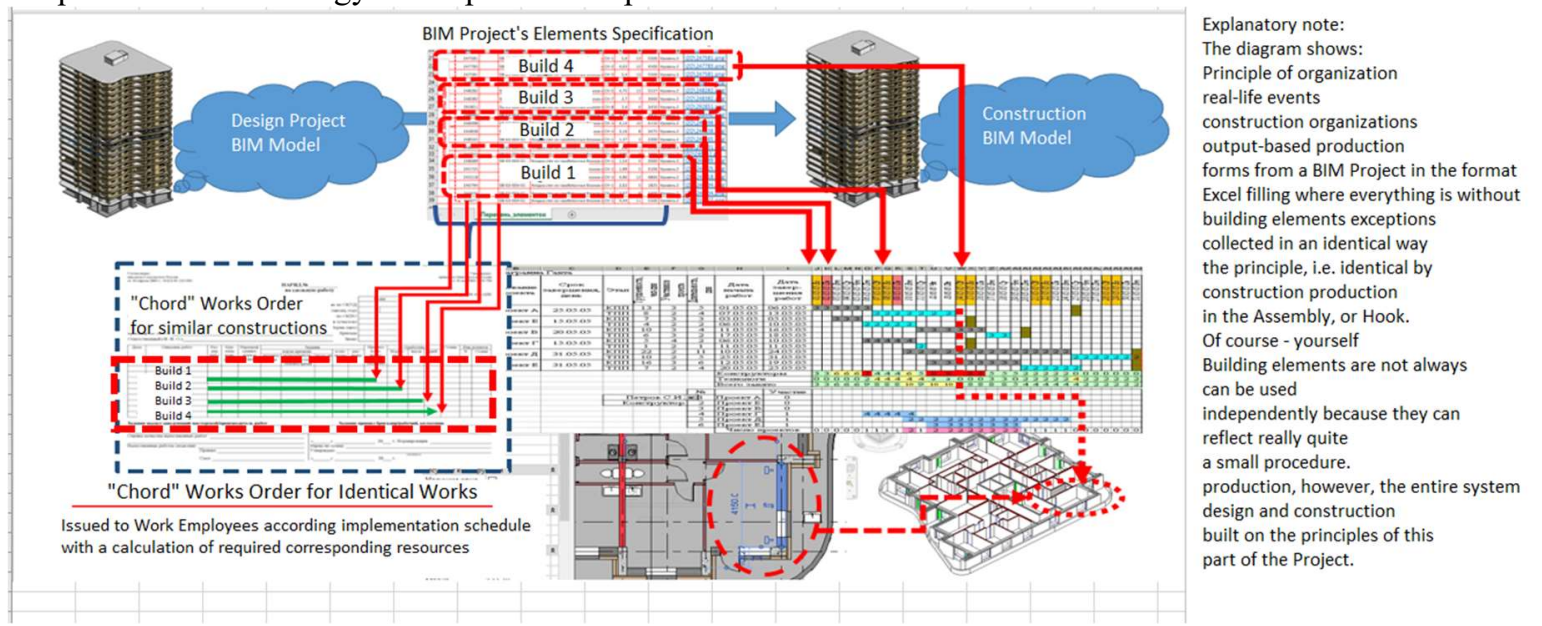

Figure 3: BIM-Model Elements Construction Activities Organization

\section{Conclusions}

Thus, the application a BIM-oriented paradigm for organizing construction production ensures fundamental compatibility with Industrialization 4.0 , as well as creates strategic prerequisites for digitalization of the entire construction industry in such a format when a full cycle is ensured.

\section{Acknowledment}

The work is performed according to the Russian Government Program of Competitive Growth of Kazan Federal University.

\section{References}

[1] Gabdullin, L. V., Islamov, K. F., \& Khamitov, I. M. (2019). Small construction business: problems and solutions (Naberezhnye Chelny, Tatarstan, Russia). AD Alta - Interdisciplinary ResearchJournal, 9, 23-25.

[2] Islamov, K. F., \& Khalikov, D. A. (2016). The structure of the information model of the classification system for thermal insulation materials. Basic research, 7, 40-45.

[3] Sibgatullin, E. S., \& Islamov, K. F. (2016). Determination of the bearing capacity of homogeneous plates and shells under high-cycle loading. Basic research, 6, 107-111.

[4] Islamov, K. F., Khalikov, D. A. (2016). The structure of the information model of the classification system of thermal insulation materials. Basic research, 7, 40-45. 
[5] Pakidov, O. I. BIM basics: Information modeling for builders. Internet resource http://isicad.ru/ru/articles/Pakidov/BIM-building-book-3.pdf

[6] Code of Rules SP 301.1325800.2017 (2017). Information modeling in construction. Work organization rules by production and technical departments. (approved by the Order of the Ministry of Construction and Housing and Communal Services of the Russian Federation No. 1178/pr dated August 29, 2017).

[7] Code of Rules SP 301.1325800.2017 (2017). Information modeling in construction. Rules for the organization of work by production and technical departments. (approved by the order of the Ministry of Construction and Housing and Communal Services of the Russian Federation of August 29, 2017 N 1178/pr). 